\title{
Better health for children in resident care
}

\author{
Leon Polnay, Adam Glaser, Vidya Rao
}

Children in community homes are a small, but very important group from the perspective of child health and mental health services. Young people are best cared for in their own homes, although the need for residential 'homes' has been recognised since the sixteenth century, when the dissolution of the monasteries by Henry VIII led to local parishes having to provide shelter for the destitute and handicapped. More recently, children's routes into care are usually through abuse or neglect. The proportion of those 'looked after' by local authorities who are in residential care has declined from $29 \%$ in 1981 to $19 \%$ in 1992 nationally. ${ }^{1}$ This decline reflects the drive to keep children within their own homes whenever possible and to attempt to foster those when this is not an available option. Consequently the young people remaining in residential care are often those with the most severe behavioural and mental health disturbances.

The 1989 Children Act identifies residents of community homes as children in need, with a requirement that each young person has an individual health care plan. ${ }^{2}$ 'Health of the Nation Targets' ${ }^{3}$ with regard to teenage pregnancy, sexually transmitted disease, suicide, smoking, and poor diets are particularly important in this group, who for some indicators may form a large proportion of the total. The British Paediatric Association report Health Needs of School Age Children recommended that the health needs of children 'looked after' be met through a discrete programme of care that should be included within the contract for community services. Despite numerous initiatives identifying the special requirements of this vulnerable and disadvantaged cohort of young people few designated services exist to meet their complex and often highly specific health needs.

The problem

Initiatives to improve the health care of young people in residential care are needed in recognition of:

(1) Concern about difficulties in communication regarding individual resident's health needs.

(2) Awareness of mental health problems that are not being properly addressed.

(3) Concern that these young people, although in greater need, miss out on the health services that should be available to all,
Table 1 The multidisciplinary team

\begin{tabular}{lll}
\hline Social services & Education & Health \\
\hline -Policy officer & $\begin{array}{c}\text {-Educational } \\
\text { psychologist }\end{array}$ & $\begin{array}{c}\bullet \text { Community } \\
\text { paediatrician }\end{array}$ \\
$\begin{array}{c}\text {-Director of } \\
\text { residential care }\end{array}$ & $\begin{array}{c}\text {-School welfare } \\
\text { officer }\end{array}$ & $\begin{array}{c}\text { adolescent } \\
\text { psychiatrist }\end{array}$ \\
$\begin{array}{c}\text {-Social worker } \\
\text { training officer }\end{array}$ & & $\begin{array}{c}\text {-School nurse } \\
\bullet \text { Clinical } \\
\end{array}$ \\
& & psychologist \\
\hline
\end{tabular}

such as immunisations, health surveillance, and health promotion.

(4) Conviction that paediatricians have a role to act as health advocates for this group who often have no effective voice of their own.

(5) Recognition that there is no effective mechanism for providing a comprehensive health needs assessment and health care plan for residents of community homes, despite this being a requirement of the 1989 Children Act.

(6) Acknowledgement that this cohort have a high incidence of school non-attendance.

(7) Acceptance that their needs present a major problem to not only social services but additionally to educational and community child health services. Local multidisciplinary groups are necessary to investigate, improve, and develop the physical and mental health provision, as well as health promotion, for the young people in residential care.

\section{Multidisciplinary approach}

Successful care of young people in residential care requires a joint children's service plan to provide an infrastructure that facilitates information sharing and communication between the agencies involved. This is rarely achieved in other situations, although with commitment from all parties the benefits are palpable. Key personnel are drawn from health, education, and social services departments (table 1).

\section{Identification of health needs of the individual}

The young person's family experiences and history of multiple placements may lead to their health needs being overlooked or neglected. Consequently every person moving into a community home must have a comprehensive personal health record combining a full medical history with an ongoing record of health needs and services received. This should contain the type of information that parents would usually have about their own child's medical history.
Correspondence to: Dr Polnay. 
Table 2 Composition of questionnaire pack

\begin{tabular}{|c|c|}
\hline Section of pack & Areas covered in questionnaire \\
\hline Background information & $\begin{array}{l}\text { Family, reason for residential care, length of time in } \\
\text { residential care, facilities for individual in community } \\
\text { home, for example own bedroom, privacy }\end{array}$ \\
\hline Modified Trent Lifestyle Survey ${ }^{6}$ & $\begin{array}{l}\text { General information, diet, injury, exercise, leisure } \\
\text { activities, alcohol, smoking, illegal drugs, use of } \\
\text { medicines, health checks, stress and feelings, sexual } \\
\text { health (modified to include more information on sexual } \\
\text { activity, sexually transmitted diseases and pregnancy), } \\
\text { extra section on hospital visits including self harm }\end{array}$ \\
\hline $\begin{array}{l}\text { CARALOC } \text { questionnaire }^{7 \star} \\
\text { Fears score }^{8}\end{array}$ & $\begin{array}{l}\text { Children's attribution of responsibility and locus of control } \\
\text { Presence or absence of fear in } 39 \text { everyday situations, for } \\
\text { example dark, being alone, reading to the class, seeing } \\
\text { the doctor }\end{array}$ \\
\hline Depression scale ${ }^{9}$ & $\begin{array}{l}\text { Somatic, emotional, and behavioural manifestations of } \\
\text { depression }\end{array}$ \\
\hline Rutter A questionnaire $^{10}$ & $\begin{array}{l}\text { Completed by key worker. Screening test for behaviour } \\
\text { problems with conduct and emotional subscores }\end{array}$ \\
\hline $\begin{array}{l}\text { Health related quality of life } \\
\text { questionnaire }\end{array}$ & $\begin{array}{l}\text { A generic multiattribute health status classification. Eight } \\
\text { attributes are covered: vision, hearing, speech, } \\
\text { ambulation, dexterity, emotion, cognition, and pain }\end{array}$ \\
\hline
\end{tabular}

*The CARALOC scale, children's attribution of responsibilities and locus of control, is an indication of children's conviction that they through their actions can influence events rather than being powerless with outside forces dictating outcome.

ALTERNATIVE TO THE 'LOOKED AFTER' MEDICAL

Traditionally all young people undergo a medical examination on entering residential care, these are followed by annual repeat check-ups. These consultations are frequently avoided by the young people who find them intrusive, intimidating, and unhelpful. An additional, and possibly alternative, approach is to obtain information through the use of self completed questionnaires. In our service a questionnaire pack is completed by the young person with or without assistance from their key residential social worker. It consists of seven sections and can be completed in approximately 60 minutes if no learning difficulties exist (table 2).

The package is explained to the young people and staff so that they are aware of its contents and intended benefits. They can choose to complete them on their own, with their key worker or decline to take part. The CARALOC, depression, fears and Rutter A scales are scored; the others contain qualitative information. Feedback from the questionnaire is from one of the multidisciplinary team's paediatricians or school nurses. The young person has a choice of venue, for example in the community home, school, or clinic. Additionally they can be seen in private or with their key worker or another chosen person and they can choose a male or female member of the team. The information is confidential to the team and the young person (with the exception of child protection issues or if the young person is in danger). Agreed information is shared with the young person's social worker to form the basis of their health care plan. The resultant recommendations are reviewed monthly by the team ensuring that both appropriate actions are taken and followed through.

Health promotion in community homes Many of the issues identified through the questionnaires will require a health promotion approach rather than a need for the more traditional medical diagnosis and treatment. This should be addressed in one or more of three ways: group work, individual health promotion, and staff support.

We run 'group sessions' in blocks of six weekly sessions. Two team members are involved in each session. Some young people request individual health promotion advice. This is provided through a series of visits by a team member to the home. Support and advice is offered to residential care staff enabling them to undertake health promotion to complement, and reinforce, that offered by the core team.

\section{Health training for residential social workers}

Residential social workers are rarely given training on the health needs of children and their knowledge is often poor (L Polnay et al, 1993, unpublished). This reflects their overall lack of training: Utting found that $75 \%$ had no formal instruction and $45 \%$ had been in post for under two years. ${ }^{5}$ Schemes to improve the health of looked after young people must remedy this. Courses should be run on a regular basis with adequate follow up. To meet the health requirements of looked after youngsters sessions should ideally be given by the following: community paediatrician, child and adolescent psychiatrist, clinical psychologist, sexual health adviser, prostitute outreach worker, school nurse, police officer (drug squad), pharmacist, child protection trainer, and diabetic liaison nurse.

\section{Building for the future}

The major challenge presented by these youngsters is the provision of services for a cohort of children who frequently fall through the net provided by all the major services, including education. Even where access is ensured, the health problems needing to be addressed are often complex and long standing. They require intensity, perseverance, and continuity of care for a successful outcome. Individual health care plans are just one component of the total strategy, which additionally depends upon the provision of a care environment that is both understanding and supportive of the general and mental health needs of the youngsters. Health promotion, including adequate sex education, is essential. Residential social workers often lack information and knowledge in these areas. Consequently they may be acting upon misinformation that can be dangerous as well as unhelpful. ${ }^{13}$ Training programmes for residential social workers must be a feature of any future improvements.

Partnership and strong teamwork at all levels is needed for success. Common commitment and ownership of initiatives will ensure that the involved agencies work closely together. Each will be able to identify barriers, within their own organisation, to better health care and to initiate action to overcome these. Local social service departments must place health high on their agenda if improved services are to be established in conditions where maintaining even the present level of commitment is difficult. 
QUESTIONNAIRE PACK

We have found questionnaires useful in the identification of health, mental health, and health promotion needs. They add vital information to that provided by the yearly medical reports. The latter have frequently been confined to physical health, not addressing mental health and health promotion issues. The questionnaires are generally popular with the young people, who feel that they are being asked directly about their own health.

\section{MEDICAL CONSULTATIONS}

There are functional obstacles to a successful medical consultation with residents of community homes. These are frequently viewed with trepidation and fear while being perceived as threatening with loss of control. The fixed times for clinics and the shifts worked by individual residential social workers mean that appointments need to be carefully planned. Ideally the escort should be someone who the young person is comfortable with, has been chosen by them, and can provide continuity in this role. Escorting is far more than the physical delivery of the young person to an appointment, but requires the necessary skills to support them and facilitate the consultation without intruding on the young person's communication with the paediatrician. These skills are not always present and should be addressed in training programmes for residential social workers.

\section{DEVELOPING TRUST}

Young people in residential care frequently experience only short term relationships with many professionals including teachers, social workers, and the medical profession. The causes are staff turnover and frequent moves of the looked after young people. A compulsory feature of new initiatives must be the intention to provide more than a transient involvement. This is necessary to build up trust with the young person, and other involved professionals (for example key worker), and to ensure that identified needs are actually met. This requires protected time by professionals involved, as well as the ability to overcome frustrations when initial appointments are not kept. Persistence, patience, and ingenuity are necessary to establish a regular series of appointments. Another component of building trust is letting the young person have control and ownership of the assessment process. This, in itself, may be a novel experience for both parties. The professional must accept the priorities of the young person rather than their own and address reports to the young person rather than their key worker. These are new patterns of working that we have to learn but are in the spirit of the 1989 Children Act and should hopefully generalise to other areas of clinical practice.
INFORMATION GATHERING AND DISSEMINATION In addition to face to face contact with the young people and their residential social workers much time will be needed by team members in pursuit of details relating to the young people's medical history. Important information, such as a family history of $\mathrm{X}$ linked mental handicap or of previous contact with paediatricians or child psychiatrists, is frequently revealed.

If referrals are required to other medical services, the young person, their escort, and the receiving physician may require special preparation if the consultation is to be a success. Liaison may be required with other agencies to ensure that any special difficulties, for example ordering repeat prescriptions or having access to their own medication, are properly understood.

\section{Conclusions}

Young people in residential care represent a special needs group whose lifestyle and circumstances present major obstacles to the provision of adequate health care. Initiatives addressing this issue are required by statute. If successful the benefits will be tangible and will ensure the inclusion of all young people being looked after, continuity of health care, and increased accessibility of health services. The integrated multiagency approach required will provide a model for other joint service plans.

Meanwhile for initiatives to succeed commitment and continuity of care are essential if we are to overcome both the inertia in the care system and the mistrust in the young people themselves.

1 Audit Commission. Seen but not heard: co-ordinating commu nity child health and social services for children in need. nity child health and

2 Children Act guidelines and regulations. Vols $3+4$. London: HMSO, 1989.

3 Department of Health. The health of the nation targets. London: HMSO, 1991.

4 British Paediatric Association. Health needs of school age children. London: BPA, 1995.

5 Utting W. Children in the public care. London: HMSO, 1991

6 Roberts H, Dengler R, Burley J, Zamorski A. Trent health lifestyle survey of young people. Report to Trent Regional Health Authority. Nottingham: Department of Public Health Medicine and Epidemiology, University of Notting ham, 1994.

7 Gammage P. Children and schooling. London: George Allen and Unwin, 1982.

8 Ollendick TH. Reliability and validity of the revised fear survey schedule for children (FSSC-R). Behav Res Ther 1983; 21 : $685-92$.

9 Birleson P. The validity of depressive disorder in childhood and the development of a self-rating scale: a research report. $f$ Child Psychol Psychiatry 1981; 22: 73-8.

10 Rutter M, Tizzard J, Whitmore K. Education, health and behaviour. London: Longmans, 1970.

11 Feeny D, Furlong W, Boyle M, Torrance GW. Multiattribute health status classification systems: health utilities index. Pharmacoeconomics 1995; 7: 490-502.

12 Torrance GW, Furlong F, Feeny D, Boyle M. Multiattribute preference functions: health utilities index. Pharmacoeconomics 1995; 7: 503-20.

13 de Cates C, Trend U, Buck C, Ng Y, Polnay L. Services for children in residential care. In: Spencer C, ed. Progress in community child health. London: Churchill Livingstone, 1995. 